\title{
Effects of season and reproductive state on lipid intake and fatty acid composition of gastrointestinal tract contents in the European hare
}

\author{
F. D. Popescu • K. Hackländer • W. Arnold • \\ T. Ruf
}

Received: 21 December 2010/Revised: 28 January 2011/ Accepted: 31 January 2011/Published online: 17 February 2011

(C) The Author(s) 2011. This article is published with open access at Springerlink.com

\begin{abstract}
We investigated lipid content and fatty acid (FA) composition of gastrointestinal tract contents in freeliving, herbivorous European hares (Lepus europaeus). Mean crude fat content in hare stomachs and total gastrointestinal (GI) tracts was higher than expected for typical herbivore forages and peaked in late fall when hares massively deposited body fat reserves. Changes of FA proportions in different parts of the GI-tract indicated a highly preferential absorption of polyunsaturated fatty acids (PUFA). A further reduction of PUFA content in the caecum, along with the appearance of odd-chained FAs in caecum, caecotrophes, and colon content, pointed to a biohydrogenation of PUFA in the hare's hindgut. GI-tract contents showed significant seasonal changes in their FA composition. Among PUFA, $\alpha$-linolenic acid peaked in spring while linoleic acid was predominant in late summer and fall, which probably reflected changes in the plant composition of forage. However, independent of seasonal changes, GI-tracts of lactating females showed a significantly (+33\%) higher content of linoleic acid, a FA that is known to increase reproductive performance in European
\end{abstract}

Communicated by I. D. Hume.

F. D. Popescu - W. Arnold · T. Ruf

Research Institute of Wildlife Ecology, University of Veterinary

Medicine Vienna, Vienna, Austria

K. Hackländer

Department of Integrative Biology and Biodiversity Research, Institute of Wildlife Biology and Game Management, University of Natural Resources and Life Sciences, Vienna, Austria

F. D. Popescu $(\bowtie)$

Institute of Animal Pathology, Vetsuisse Faculty,

University of Berne, Bern, Switzerland

e-mail: francesca.popescu@itpa.unibe.ch hares. This finding suggests that lactating females actively selected dietary plants rich in linoleic acid, a PUFA that may represent a limited resource for European hares.

Keywords Brown hare - Essential fatty acids .

Polyunsaturated fatty acids - Caecotrophy .

Nutrient content $\cdot$ Reproduction

$\begin{array}{ll}\text { Abbreviations } \\ \text { FA } & \text { Fatty acids } \\ \text { PUFA } & \text { Polyunsaturated fatty acids } \\ \text { SFA } & \text { Saturated fatty acids } \\ \text { MUFA } & \text { Monounsaturated fatty acids } \\ \text { GI } & \text { Gastrointestinal } \\ \text { CT } & \text { Caecotrophes } \\ \text { SI } & \text { Small intestine } \\ \text { DM } & \text { Dry mass }\end{array}$

\section{Introduction}

The dry matter fat content in typical food plants of herbivorous mammals, e.g. on pastures, is typically less than 3.5\% (Palmquist and Jenkins 1980). Thus, dietary fat may represent a limited resource for these species. Expectedly then, herbivores such as horses and cattle are highly susceptible to variation in dietary fat content, which can, for instance, profoundly affect milk fatty acid (FA) composition during lactation (e.g. Hoffman et al. 1998; Bargo et al. 2003; Chilliard et al. 2000). In the herbivorous European hare (Lepus europaeus), dietary fats also play a crucial role for reproduction. Lactating females rapidly increase food consumption in response to low dietary fat content, but still 
transfer less milk energy (per unit body weight) to young than animals on a high fat diet (Hackländer et al. 2002; Valencak and Ruf 2009). To some degree, variation in the fat content of natural diets may be buffered by the deposition of body fat stores after the reproductive season, which occurs in both sexes (Fig. 1; see also Flux 1967; Zörner 1996). Body fat stores are, however, depleted over summer, which in males may be due to increased activity associated with male-male aggression and in females involves direct transfer of lipid stores to the mammary gland (Valencak et al. 2009). Consequently, dietary fat content may have a strong impact on reproductive success in this species either directly or via its effects on the turnover rate of body fat stores.

Natural diets of hares may, however, differ not only in total fat content but also in their FA composition. Arguably, this variation should be particularly important when it concerns the two major plant PUFA linoleic acid (C18:2n6) and $\alpha$-linolenic acid (C18:3n-3). This is because linoleic acid and $\alpha$-linolenic acid, in contrast to saturated (SFA) and monounsatured fatty acids (MUFA), cannot be synthesized de novo in mammals, but must be obtained from the diet. Among other functions, PUFA can also affect reproductive performance. Recently, Tufarelli et al. (2010) found that dietary PUFA composition in European hares, particularly n-6 PUFA supplementation, significantly increased the number of successfully weaned young compared with females on an isocaloric MUFA supplemented diet. An important role of n-6 PUFA uptake has been also suggested for muscular performance and maximum running speed in mammals (Ruf et al. 2006), another trait that directly affects fitness in species such as hares, which evade predators by fast speed.

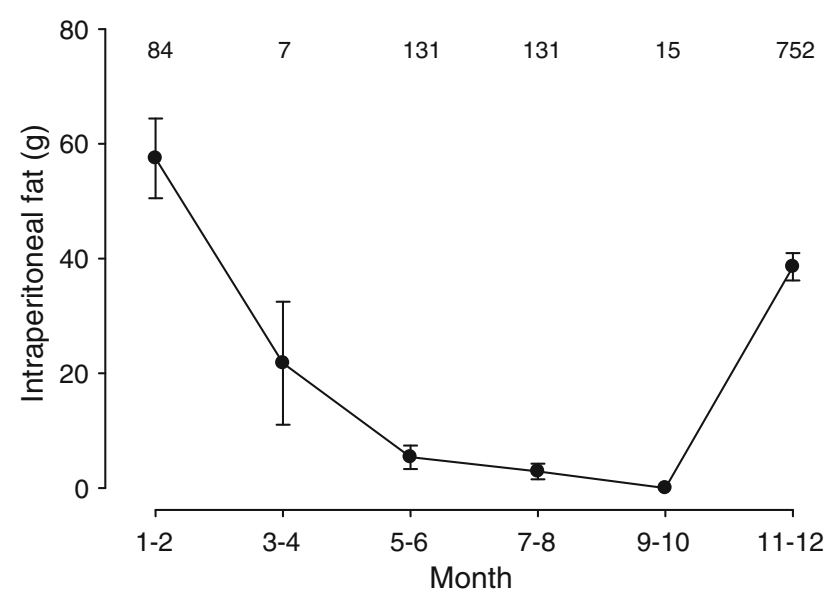

Fig. 1 Seasonal change of intraperitoneal fat content (w/o gonadal fat depots) in free-living European hares (both sexes) shot at bimonthly intervals in Lower Austria. The numbers above the symbols indicate sample sizes. Means $\pm 95 \%$ confidence intervals
Despite this evidence for an important role of dietary fat content and composition, relatively little is known about fat intake, digestion and FA uptake in the GI-tract of European hares. Therefore, we analysed contents of all parts of the GI-tract of free-living hares, collected at all four seasons. We were particularly interested to see whether the wellknown seasonal cycle of body fat deposition and depletion is merely due to differences in energy expenditure or is also reflected in seasonal changes of food quality, namely dietary fat content.

Further, contents of hare stomachs and small intestines should provide an index of not only total fat intake but also of the uptake and absorption of PUFA, relative to SFA and MUFA. This is because hares are hindgut fermenters in which - in contrast to ruminants-little or no hydrogenation of unsaturated FAs by intestinal microorganisms should be expected before their absorption (Doreau and Ferlay 1993; Hoffman et al. 1998). Consequently, determining the FA composition of GI-tract contents should allow us to see (i) if there are significant seasonal changes of FA composition, (ii) if there is any indication for preferential uptake of any FA classes or specific FA and (iii) if there is evidence for a preferential absorption of certain FA. Finally, we intended to examine whether any of the variables investigated, in particular possible preferences for certain FA, may differ between sexes and, in particular, may deviate in lactating females that have dramatically increased energy demands (Hackländer et al. 2002; Valencak et al. 2009).

\section{Materials and methods}

Animals and sample collection

To determine seasonal changes in the size of body fat deposits intraperitoneal fat (but not gonadal depots) were removed from a total of 1120 European hares, and fresh weight was determined to the nearest $0.1 \mathrm{~g}$. Hares were shot by local hunters in four regions of Lower Austria $\left(48^{\circ} 11^{\prime} \mathrm{N}, 16^{\circ} 42^{\prime} \mathrm{E}\right.$, elevation $\left.140 \mathrm{~m}\right)$ between 2001 and 2005. Since more hares were shot during the hunting season, compared to the breeding season, sample sizes varied (Fig. 1).

GI-tracts were collected from a subsample of hares shot in February $(N=33)$, May $(N=36)$, August $(N=32)$ and November $(N=39)$ in the year 2004 only. Hare carcasses were transported to the lab immediately after the kill and kept in a cold room $\left(+5^{\circ} \mathrm{C}\right)$ prior to dissection on the same day to minimise post mortem autolysis of the digestive tract. Typically, animals were shot in the morning, before noon. Animals $(N=140)$ were classified into two age classes, subadults $(N=35)$ and adults $(N=105)$, 
according to the weight of the dried eye-lens (Suchentrunk et al. 1991). The mean body weight was $3963 \pm 641 \mathrm{~g}$.

The GI-tract was divided into stomach, small intestine (SI), caecum and colon (Nickel et al. 1984). Full weights and weights of the content of each part were recorded, and contents were stored at $-18^{\circ} \mathrm{C}$ for later nutrient and FA analyses. Clearly distinguishable soft, pale agglomerates found in the stomach content were considered caecotrophes (CT) and analysed separately $(N=18)$. All data on stomach contents thus refer to the content of this organ after removal of all CT.

\section{Lipid and fatty acid analyses}

GI-tract contents were dried at $60^{\circ} \mathrm{C}$, and $1 \mathrm{~g}$ of the each sample was further dried for $2 \mathrm{~h}$ at $105^{\circ} \mathrm{C}$ to determine dry matter. Crude fat was analysed by Soxhlet's procedure extraction (using petrol ether as solvent) from $1 \mathrm{~g}$ of the sample, and the difference in weight before and after extraction was calculated.

To determine FA contents, we used FA methyl ester (FAMES) FA transesterification (Garces and Mancha 1993), separation, identification and quantification, based on peak areas obtained by gas chromatography (Eder 1995). A quantity of $300 \mathrm{mg}$ of GI-tract content sample was used to analyse FAs composition. The sample was heated for $2 \mathrm{~h}$ with a reagent mixture containing methanol: toluene: 2,2-dimetoxypropane: $\mathrm{H}_{2} \mathrm{SO}_{4}$ (39:20:5:2, by volume). Two phases were formed, the upper one containing the FAMES ready for GC analysis (Perkin Elmer Autosystem XL with Autosampler and FID; Norwalk, USA) using a capillary column (HP INNOWax, $30 \mathrm{~m} \times$ $0.25 \mathrm{~mm}$; Hewlett Packard, USA). The methyl esters of SFA (C14:0, C15:0, C16:0, C17:0 and C18:0), MUFA (C16:1 and C18:1) and PUFA (C18:2n-6 and C18:3n-3) were separated under gas chromatographic conditions and identified comparing their retention time with those of standards (Sigma-Aldrich, St. Louis, USA).

\section{Statistical analyses}

All statistical analyses were carried out using the statistical package $\mathrm{R}$ ( $\mathrm{R}$ development core team 2010). To lower the problems caused by a multiplicity of tests (if data on all measured FAs were compared individually), we reduced statistical analyses to the following response variables: Total lipid content, proportions of SFA, MUFA and PUFA among FAs, and proportions of linoleic acid and $\alpha$-linolenic acid within the PUFA class. To test for differences between samples collected from different parts of the GItract (of the same animals), we used repeated measurement ANOVAs by computing linear mixed effects models using library nlme (Pinheiro et al. 2009). In these models,
GI-tract section was entered as a fixed factor and animal ID as the random factor.

To obtain estimates of potentially absorbable nutrients, we subsequently computed means of all of the above response variables over all GI-tract sections. This computation of means also included colon contents because not only soft but also hard faeces are a potential nutritional source in leporids, including hares (Hirakawa 2001). None of the results was, however, significantly altered by inclusion or exclusion of colon contents. We tested for possible effects of body weight, sex, age, season and lactation among females, on these mean contents using simple linear model ANOVAs.

Residuals from all models were inspected for non-normality (Shapiro-Wilks tests) and heterogeneity of variances (Levene tests), but none of these tests indicated significant problems with the model structure. Starting with full models including all predictor variables, we reduced model structures in a stepwise procedure by eliminating non-significant terms. This included age-class in all cases, which therefore is not further mentioned. For all ANOVAs we computed marginal (Type III) sums of squares. We report degrees of freedom, $F$ and $P$ values from ANOVAs for non-significant terms obtained from full models, and for significant terms obtained from final, reduced models. In all graphs, data are presented as means $\pm 95 \%$ confidence intervals to ease comparisons between subsamples.

\section{Results}

\section{Lipid content}

Total lipid content differed significantly between all fractions collected from the GI-tract $\left(F_{4,138}=364.178\right.$; $P<0.001)$. As illustrated in Fig. 2, lipid content significantly increased between stomach and small intestine, and was significantly lower in all posterior fractions.

Comparing means from all GI-tract fractions, we found that lipid content was significantly different between seasons $\left(F_{3,139}=13.2 ; \quad P<0.001\right)$. Mean lipid content showed an early peak in May and reached maximum values in November (Fig. 3). Lipid content was unaffected by body weight $\left(F_{1,135}=1.92 ; P=0.167\right)$, sex $\left(F_{1,135}=\right.$ $0.001 ; P=0.966)$ and age $\left(F_{1,135}=1.94 ; P=0.165\right)$. Also, among females, mean lipid content of GI-tract contents was not different between lactating and non-lactating animals $\left(F_{1,80}=0.004 ; P=0.945\right)$.

Fatty acids

Fatty acid composition of lipids drastically changed between contents of different sections of the GI-tract 


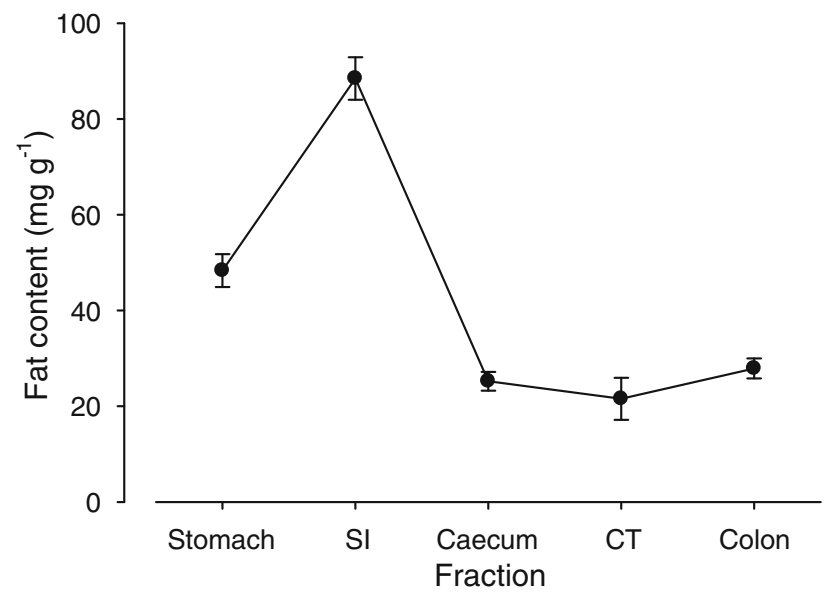

Fig. 2 Crude fat content of digesta in different fractions of the gastrointestinal tract of free-living European hares. SI small intestine, $C T$ caecotrophes. Means $\pm 95 \%$ confidence intervals

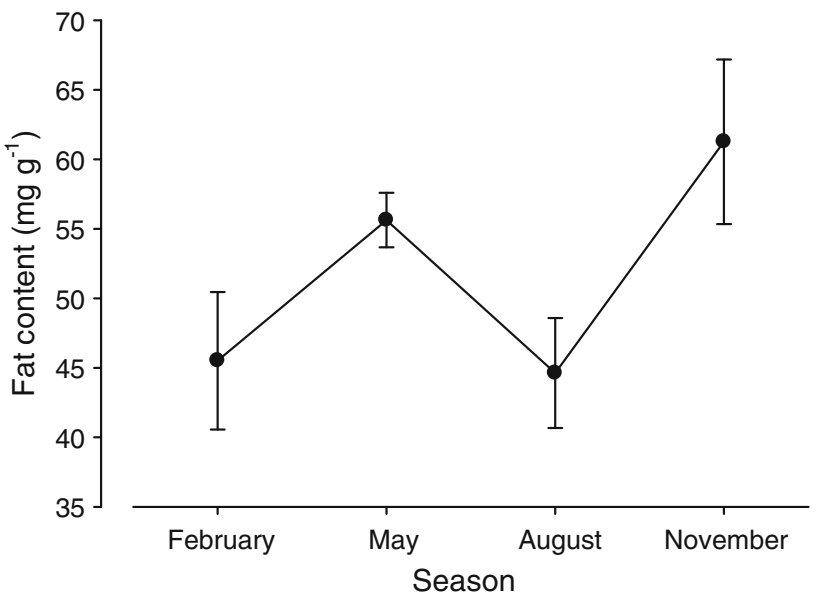

Fig. 3 Mean crude fat content of digesta in the gastrointestinal tract of European hares as a function of season. Means $\pm 95 \%$ confidence intervals

(Fig. 4a). PUFA content significantly decreased along the GI-tract $\quad\left(F_{4,403}=1059.8 ; \quad P<0.001\right), \quad$ while $\quad$ SFA increased by a similar extent $\left(F_{4,403}=786.7 ; P<0.001\right)$. The proportion of MUFA increased only slightly but significantly $\left(F_{4,403}=119.4 ; P<0.001\right)$ between stomach and posterior fractions, compared to the changes in PUFA and SFA content (Fig. 4a).

Among PUFA, there were significant differences between the GI-tract fractions for both linoleic acid $\left(\mathrm{C} 18: 2 \mathrm{n}-6 ; F_{4,403}=326.8 ; P<0.001\right)$ and $\alpha$-linolenic acid $\left(\mathrm{C} 18: 3 \mathrm{n}-3 ; F_{4,403}=465.6 ; P<0.001\right)$. However, while $\alpha$ linolenic acid continuously decreased between stomach and caecum, linoleic acid proportion increased from stomach to small intestine and decreased only in the posterior GI-tract fractions (Fig. 4b). Mean proportions of all individual FA determined are given in Table 1.
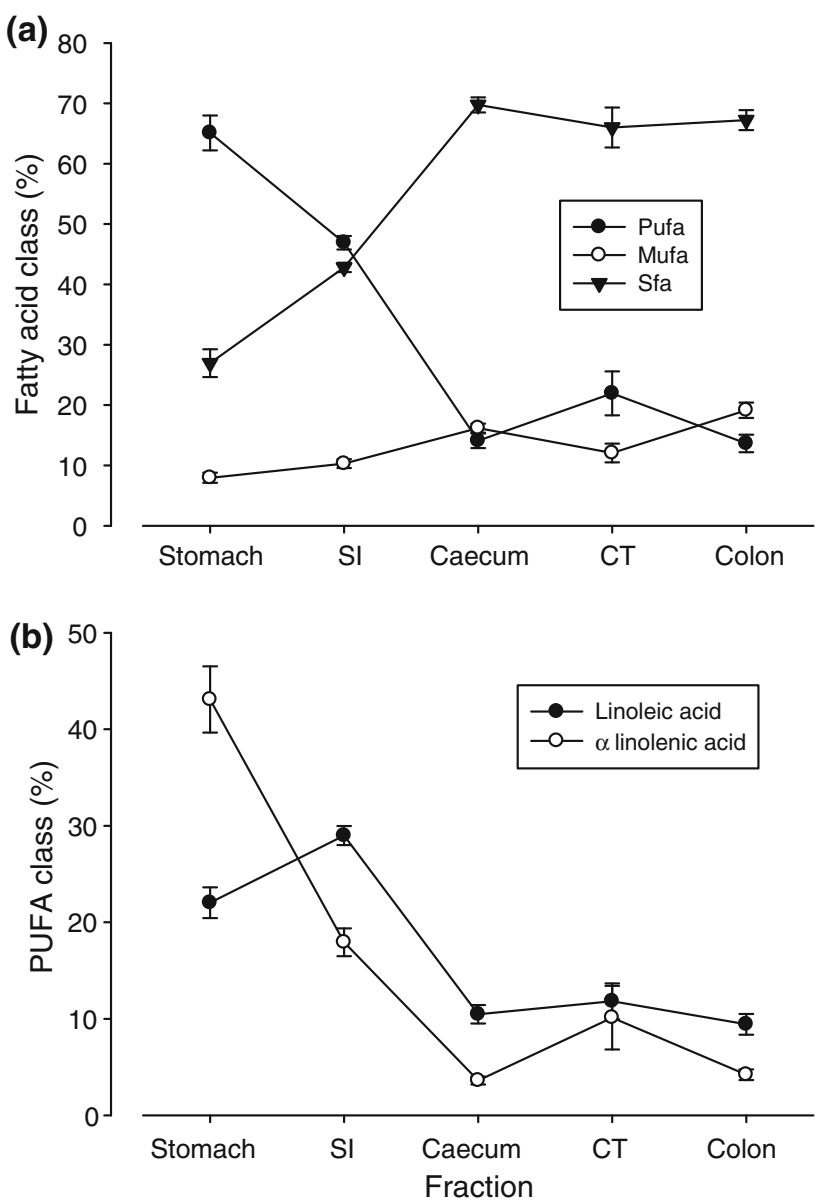

Fig. 4 Fatty acid content in different fractions of the gastrointestinal tract of European hares. Means $\pm 95 \%$ confidence intervals. a Proportions of polyunsaturated (PUFA), monounsaturated (MUFA) and saturated (SFA) fatty acids. b Proportions of linoleic acid (C18:2n-6) and $\alpha$-linolenic acid (C18:3n-3) within PUFA

Season had a strong effect on mean GI-tract contents of PUFA $\left(F_{3,139}=101.0 ; P<0.001\right)$, SFA $\left(F_{3,139}=75.2\right.$; $P<0.001)$ and MUFA $\left(F_{3,139}=23.6 ; P<0.001\right)$. PUFA content was significantly increased in May and August, compared to February and November (Fig. 5a), and the inverse pattern was found for SFA content. Virtually, the same pattern of seasonal changes was found if stomach contents alone, rather than total GI-tract contents were analysed (not shown). The fact that changes in PUFA content mirrored those in SFA content was due to a strong negative correlation between these FA classes $(R=$ $-0.945, P<0.001)$. In comparison, correlations of MUFA with both SFA $(R=0.346, P<0.001)$ and PUFA $(R=$ $-0.634, P<0.001)$ were much weaker. All major FA classes were unaffected by body weight, sex and age of the animals, or by lactation among females $(F<2.1, P>0.15$ in all cases).

The proportions of both linoleic acid $\left(F_{3,139}=65.8\right.$; $P<0.001)$ and $\alpha$-linolenic acid $\left(F_{3,139}=67.0 ; P<0.001\right)$ 

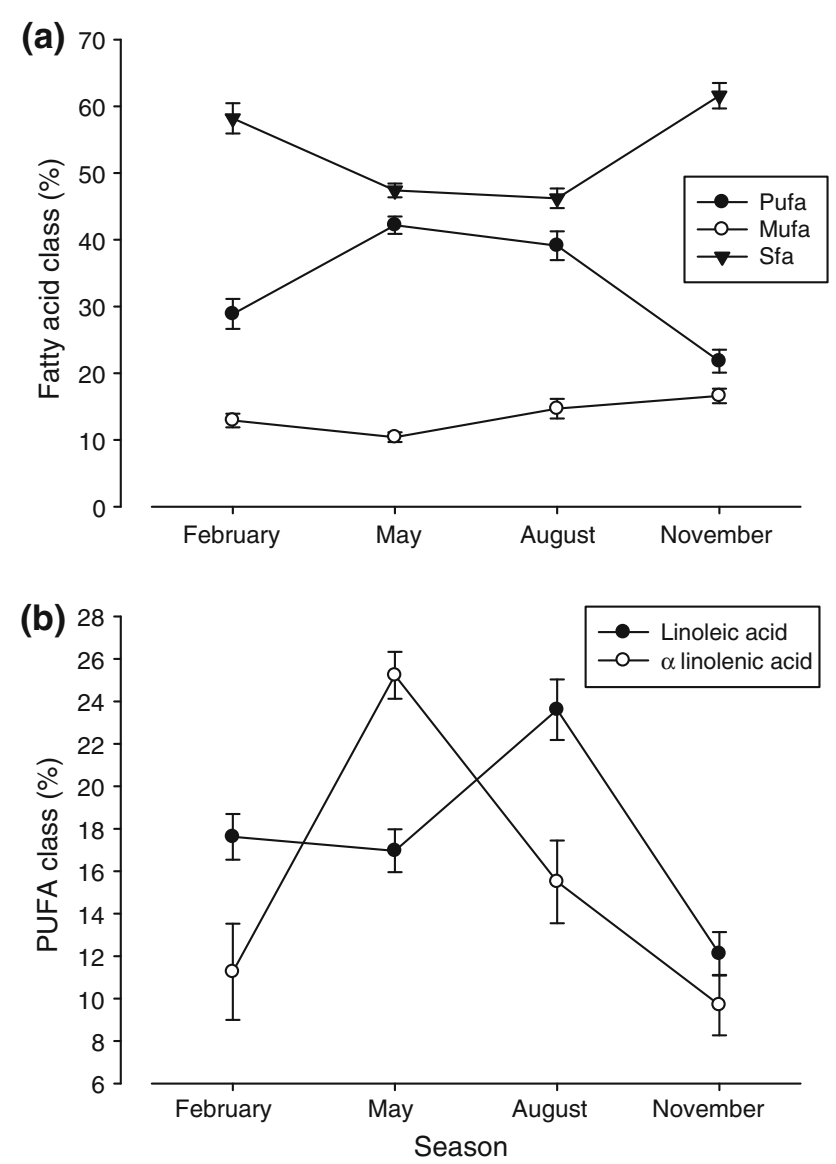

Fig. 5 Mean fatty acid proportions in the gastrointestinal tract contents of European hares as a function of season. Means $\pm 95 \%$ confidence intervals. a Proportions of polyunsaturated (PUFA) monounsaturated (MUFA) and saturated (SFA) fatty acids. b Proportions of linoleic acid and $\alpha$-linolenic acid within PUFA

significantly changed between seasons, with $\alpha$-linolenic acid reaching a peak in spring (May), and linoleic acid peaking in late summer (August; Fig. 5b). Interestingly, even after statistically adjusting for seasonal differences, mean linoleic acid content was significantly (33\%) higher in lactating than in non-lactating females (Fig. $6 ; F_{1,80}=$ 12.1; $P<0.001)$. In contrast, $\alpha$-linolenic acid content was not elevated in lactating females $\left(F_{1,80}=0.41 ; P=0.64\right)$. Neither of the two major PUFA was affected by any of the other variables investigated.

\section{Discussion}

Crude fat content of GI-tract contents

Mean crude fat content in the of hare stomach contents varied around approximately $46 \mathrm{mg} \mathrm{g}^{-1}$ (i.e. $4.6 \%$; Fig. 2), reaching a peak of $5.4 \%$ in November, and that of the entire GI-tract between approximately 4.5 and $>6 \%$, depending 


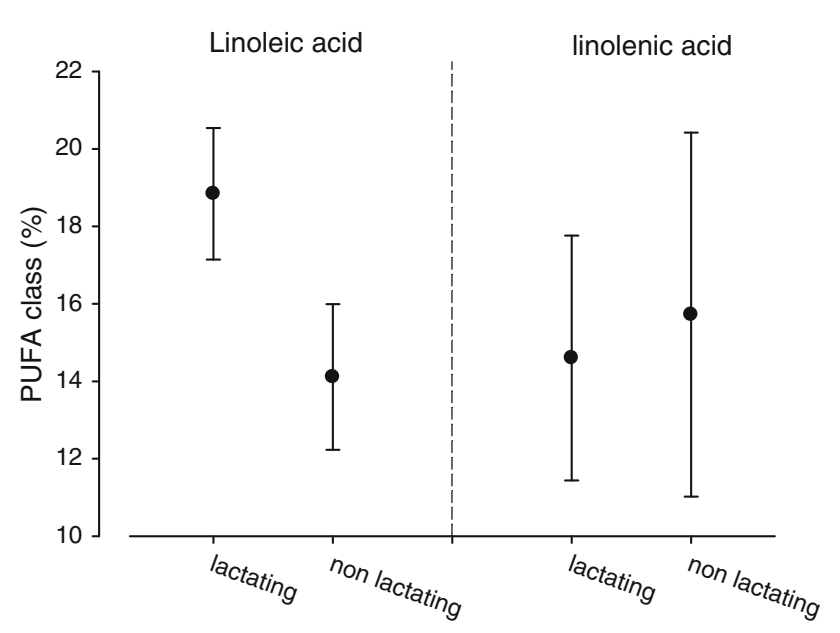

Fig. 6 Linoleic acid and $\alpha$-linolenic acid proportions in the gastrointestinal tract content of lactating and non-lactating female European hares. Means from all fractions of the gastrointestinal tract $\pm 95 \%$ confidence intervals

on the season (Fig. 3). This is somewhat higher than previous determinations of crude fat proportions from pastures, which typically range from 1.5 to $4 \%$ of DM (Palmquist and Jenkins 1980; Kuntz et al. 2006; Buccioni et al. 2008; Leiber et al. 2008). Although up to $50 \%$ of forage ether extracts can consist of non-fatty acid lipid components (waxes, chlorophyll, etc.; Palmquist and Jenkins 1980), the relatively high proportion of crude fat in European hare ingesta may indicate a preferential intake of plant parts rich in fat. Previous botanical analyses of hare stomach contents (Reichlin et al. 2006) have in fact shown clear preferences for several plant species (e.g. Glycine max, Papaver spp., Trifolium ssp., Panicum miliaceum, Medicago sativa) which either in general, or for certain parts, are characterised by above average fat content (Glycine max seeds, 18\%; sprouts, 10\%; Papaver seeds, 46-49\%; Trifolium, up to 6\%; Panicum, 4\%; Medicago, $5 \%$; CropIndex (2011), data converted to \% of DM). However, the data currently available on nutrient composition of different parts of plants (sprouts, leaves, inflorescences, seeds) - especially in weeds-are insufficient to unambiguously demonstrate selective feeding, based on stomach content analyses. Clearly, controlled experimental trials would be needed to confirm such a dietary selection. It should be noted, however, that the ability to select certain dietary nutrients as well as specific plant parts (e.g. Milton 1979; Berteaux et al. 1998; Bryant and Kuropat 1980) is well documented for other mammals. In European hares, such a preference, especially during the late-autumn fattening phase (Fig. 1), clearly would make sense given the strong impact of dietary fat on reproductive performance in this species (Hackländer et al. 2002; Valencak et al. 2009).
The comparison of crude fat contents in different parts of the GI-tract (Fig. 2) does, however, further support the view of a dietary preference for fatty plant parts. This is because mean crude fat content in the SI reached $8.8 \%$, which may be partly due to a rapid passage of highly digestible, fat-rich dietary particles from the stomach to the SI, or a facilitated removal of low-fat, fibrous particles. Note that the majority of hares in this study were shot several hours after sunrise (i.e. their last food intake; Hirakawa 1994) which provides sufficient time for such a passage (especially in lagomorphs in which the passage rate of food is quite rapid; Hirakawa 2001). In that case, the crude fat content of the diet may well have significantly exceeded that of stomach contents.

Theoretically, part of the increase in crude fat content between stomach and SI could have been due to the addition of endogenous phospholipids and cholesterol from bile and phospholipids from shed intestinal cells (Carlier et al. 1991). It seems very unlikely, however, that these sources of crude fat alone should have led to an almost doubling of its content in the SI (Fig. 2). Published data on bile FA composition (in ruminants) indicate that both $\mathrm{n}-3$ and $n-6$ PUFA content in bile is much lower $(<12 \%)$ than in the stomach and SI contents determined here (Miller and Rice 1967; Garton 1969). Therefore, any substantial addition of bile FA would have led to a much stronger change of FA composition between stomach and SI than was actually observed here, with FA composition showing a linear change from stomach to caecum (Fig. 4a).

\section{Fatty acid absorption}

The significant decrease of PUFA content in the SI compared to the stomach, and the observed simultaneous increase of SFA (Fig. 4a), indicates a preferential absorption of PUFA. Partly, this result can be attributed to the lipophilic chemical properties of these FA. The permeation of intestinal enterocyte membranes increases with chain length (Carlier et al. 1991), which is higher in dietary PUFA (C18) than in SFA (C14-18, mean chain-length 16.2 in stomach contents of hares studied here). Further, there is some evidence that absorption of PUFA is enhanced by a facilitated diffusion mechanism and may involve a specific long-chain FA binding protein (FAPB, reviewed in Carlier et al. 1991). Preferential absorption of PUFA may contribute to the relatively high proportions of PUFA in the tissues of European hares (Valencak et al. 2003) and other hindgut fermenters (Leiber et al. 2008).

Following absorption of a large fraction of PUFA in the SI, there was a further decline of PUFA proportions in the caecum. Al least part of this reduction in the amount of PUFA (which reached similar proportions in caecum contents, CT and colon contents) was almost certainly due to 
biohydrogenation by microorganisms. This fate of PUFA, i.e. the removal of their double bonds by addition of hydrogen atoms, is well known-and even more pronounced-in ruminants (e.g. Doreau and Ferlay 1993; Hristov et al. 2005), but has also been documented in hindgut fermenters. In rabbits for instance, hydrogenation results in a similar predominance of SFA in caecotrophes as observed in the present study (Leiber et al. 2008). Microbial fermentation in the caecum is also supported by our finding that odd chain-length FA (C15:0; C17:0) were virtually absent in stomach and SI contents of hares, but reached substantial proportions in the caecum, CT and colon content (Table 1). As these FA occur only in trace amounts in higher plants, but can be produced by bacteria (Vlaemink et al. 2006), it seems clear that they originated from bacterial metabolism in the hindgut.

Differentiating between the two major PUFA (Fig. 4b) gave no clear evidence for a preferential intake or absorption of either linoleic acid or $\alpha$-linolenic acid. The predominance of $\alpha$-linolenic acid in stomach contents reflects that of typical forages of herbivores (e.g. Palmquist and Jenkins 1980; Kuntz et al. 2006; Leiber et al. 2008; Meluchova et al. 2008). Originally, we had hypothesized that European hares may generally show a preferential intake of linoleic acid. This is because in cell membranes of skeletal muscle, heart and liver of this species the ratio of linoleic to $\alpha$-linolenic acid (and their longer-chained $n-6$ derivates) is actually reversed compared to typical pastures and stomach contents. This is also true for other mammalian herbivores, but the proportion of linoleic acid and its $\mathrm{n}-6$ derivates is even higher in European hares than in other mammals of comparable body size (Valencak and Ruf 2007; Ruf et al. 2006). Consequently, our present data indicate that the FA composition of tissue membranes must be governed by mechanisms that control the formation and incorporation of membrane phospholipids rather than by differential FA uptake. Still, as outlined below, this does not exclude an important physiological function of dietary selection for certain FA.

Fatty acid classes: season and reproduction

GI-tract contents showed a clear seasonal pattern of FA composition (Fig. 5). During summer, PUFA content significantly increased at the expense of SFA, and linoleic and $\alpha$-linolenic acid peaked at different times of the year. Thus, it seems that the FA composition of hare GI-tract contents closely follows the seasonal pattern of natural forage, as principally the same seasonal shifts have been observed in mixed plant samples of natural pastures in both alpine habitats (Ruf and Arnold 2008) and in a nearby western Slovakian habitat that is climatically and botanically very similar to our hare study site (Meluchova et al. 2008). The spring peak of $\alpha$-linolenic acid is almost certainly due to the fact that this FA is primarily produced during photosynthesis (Gurr et al. 1969; Kenyon and Stanier 1970) which is at its maximum during the spring growth phase of pastures. Later in the year (August/September), there is an increase in the proportion of linoleic acid, which is enriched in inflorescences and seeds (Ruf and Arnold 2008; Meluchova et al. 2008).

Whereas GI-tract contents seemed to largely reflect the FA composition of natural forage, there was one interesting exception: the significantly increased content of linoleic acid in GI-tract contents of lactating females. Since FAcompositions in the GI-tract were statistically adjusted for season, this effect cannot be attributed to the time of lactation coinciding with elevated linoleic acid availability. Theoretically, higher proportions of linoleic acid could be due to reduced absorption of this FA. However, there is neither evidence for significantly altered overall assimilation efficiency in lactating females (Valencak and Ruf 2009) nor any reason to assume that lactating hares should down-regulate the absorption of this rarer of the two essential PUFA. Consequently, the most parsimonious explanation for this finding is a genuine dietary preference of lactating females for plants or plant-parts rich in linoleic acid. This conclusion can be reached without any need for the analyses of plant FA composition because both lactating and non-lactating females were shot at randomly distributed locations at the study site indicating that average available food composition was virtually identical for both groups. The apparent ability of European hares to preferentially select plants with increased linoleic acid content is not surprising. Firstly, it has been shown that different plant species and parts show a large variation in their FA composition. For instance, linoleic acid content in dietary plants of herbivores can range from 3 to $274 \mathrm{mg} \mathrm{g}^{-1}$ (Frank et al. 1998) or, as determined in another study, from 8 to $239 \mathrm{nmol} \mathrm{mg}^{-1}$ (Hill and Florant 1999). Secondly, there is ample evidence from both field and laboratory studies that animals do in fact select food on the basis of their FA content (e.g. Frank 1994; Frank et al. 1998; Hiebert et al. 2000, 2003; Bairlein 2002; McWilliams et al. 2004; Ruf and Arnold 2008).

As mentioned before, there also is recent evidence from a hare breeding colony that supplementing the diet with oils rich in linoleic acid increases both the number of young born and weaned compared to isocaloric $\alpha$-linolenic acid-enriched and-even more so-compared to MUFA enriched diet (Tufarelli et al. 2010). Further, young of females supplied with linoleic acid-rich diet grow significantly faster between birth and weaning compared to those of females on an isocaloric SFA diet, in particular when litter size is large (i.e. $\geq 3$; Hauhart 2002). The pathways by which PUFA affect reproductive performance are not fully 
understood, but may involve altered membrane properties, effects on reproductive hormones such as steroids and prostaglandins, as well as effects on gene regulation (Mattos et al. 2000; Bordoni et al. 2006; Wathes et al. 2007). However, irrespective of the mechanisms involved it seems clear that, given its beneficial effect on reproductive performance, diet selection for linoleic acid-rich forage may well increase the fitness of lactating females.

\section{Conclusion}

This study gives some indication for preferential uptake of plant parts rich in fat and provides good evidence for enhanced PUFA absorption in free living European hares. Our findings also point to selective uptake of a specific PUFA, namely linoleic acid, by females during lactation. All of these results from our field study fit to conclusions from previous, laboratory studies, that dietary fat and PUFA composition play an important role in particular for reproduction in the European hare (Hackländer et al. 2002; Valencak and Ruf 2009; Hauhart 2002; Tufarelli et al. 2010). It is also clear, however, that insights from data on GI tract contents alone are limited and that further experimental studies are needed to clarify both the ability of European hares to discriminate food items and to assess the impact of certain dietary plants on the physiology of this species in more detail.

Acknowledgments This work was supported by the Austrian Science Fund (P17794-B06 to TR) and by the province of Lower Austria. FP was a recipient of a doctoral scholarship of University of Veterinary Medicine Vienna (von Fircks Stipendium). KH was supported by the Deutsche Wildtier Stiftung. We would like to thank Dr. F. Tataruch, Dr. T. Steineck, M.H. Le, R. Winklbauer and E. Steiger for their help. All experiments described here comply with the current laws in Austria, where the analyses were performed.

Open Access This article is distributed under the terms of the Creative Commons Attribution Noncommercial License which permits any noncommercial use, distribution, and reproduction in any medium, provided the original author(s) and source are credited.

\section{References}

Bairlein F (2002) How to get fat: nutritional mechanisms of seasonal fat accumulation in migratory song birds. Naturwiss 89:1-10

Bargo F, Muller LD, Kolver ES, Delahoy JE (2003) Production and digestion of supplemented dairy cows on pasture. J Diary Sci 86:1-42

Berteaux D, Crete M, Huot J, Maltais J, Oullet JP (1998) Food choice by white-tailed deer in relation to protein and energy content of the diet: a field experiment. Oecologia 115:84-92

Bordoni A, Nunzio MD, Danesi F, Biagi PL (2006) Polyunsaturated fatty acids: from diet to binding to PPARs and other nuclear receptors. Genes Nutr 1:95-106
Bryant JP, Kuropat PJ (1980) Selection of winter forage by subarctic browsing vertebrates: the role of plant chemistry. Annu Rev Ecol Syst 11:261-285

Buccioni A, Antongiovanni M, Petacchi F, Mele M, Serra A, Secchiari P, Minieri S (2008) Effect of dried or green herbage on vaccenic acid and conjugated linoleic acid production during in vitro rumen fermentation. Anim Feed Sci Technol 140:207-213

Carlier H, Bernard A, Caselli C (1991) Digestion and absorption of polyunsaturated fatty acids. Reprod Nutr Dev 31:475-500

Chilliard Y, Ferlay A, Mansbridge RM, Doreau M (2000) Ruminant milk fat plasticity: nutritional control of saturated, polyunsaturated, trans and conjugated fatty acids. Ann Zootech 49:181-205

CropIndex (2011) Center for new crops \& plant products data base, Purdue University http://www.hort.purdue.edu/newcrop/Indices/ index_ab.html

Doreau M, Ferlay A (1993) Digestion and utilization of fatty acids by ruminants. Anim Feed Sci Technol 45:379-396

Eder K (1995) Gas chromatographic analysis of fatty acids methyl esters. A review. J Chromatogr 671:113-131

Flux JEC (1967) Reproduction and body weights of the hare Lepus europaeus Pallas in New Zeeland. N Z J Sci 10:357-401

Frank CL (1994) Polyunsaturate content and diet selection by ground squirrels (Spermophillus lateralis). Ecology 75(2):458-463

Frank CL, Dierenfeld ES, Storey KB (1998) The relationship between lipid peroxidation, hibernation, and food selection in mammals. Am Zool 38:341-349

Garces R, Mancha M (1993) One-step lipid extraction and fatty acid methyl esters preparation from fresh plant tissues. Anal Biochem 211:139-143

Garton GA (1969) Digestion and absorption of lipids in the ruminant. Proc Nutr Soc 28:131-139

Gurr MI, Robinson MP, James AT (1969) The mechanism of formation of polyunsaturated fatty acids by photosynthetic tissue. Eur J Biochem 9:70-78

Hackländer K, Tataruch F, Ruf T (2002) The effect of dietary fat content on lactation energetics in the European hare (Lepus europaeus). Physiol Biochem Zool 75:19-28

Hauhart B (2002) Der Einfluss der Nahrung auf Reproduktion, postnatale Entwicklung und Thermoregulation beim Europäischen Feldhasen (Lepus europaeus). Diploma Thesis, University of Vienna, Austria

Hiebert SM, Fulkerson EK, Lindermayer KT, McClure SD (2000) Effect of temperature on preference for dietary unsaturated fatty acids in the Djungarian hamster (Phodopus sungorus). Can $\mathbf{J}$ Zool 78(8):1361-1368

Hiebert SM, Hauser K, Ebrahim AJ (2003) Djungarian hamsters exhibit temperature-dependent dietary fat choice in long days. Physiol Biochem Zool 76(6):850-857

Hill VL, Florant GL (1999) Patterns of fatty acid composition in freeranging yellow-bellied marmots (Marmota flaviventris) and their diet. Can J Zool 77:1494-1503

Hirakawa H (1994) Coprophagy in the Japanese hare (Lepus brachyurus): reingestion of all the hard and soft faeces during the daytime stay in the form. J Zool Lond 232:447-456

Hirakawa H (2001) Coprophagy in leporids and other mammalian herbivores. Mammal Rev 31:61-80

Hoffman RM, Kronfeld DS, Herbein JH, Swecker WS, Cooper WL, Harris PA (1998) Dietary carbohydrates and fat influence milk composition and fatty acids profile of mare's milk. J Nutr 128:2708S-2711S

Hristov AN, Kennnigton LR, McGuire MA, Hunt CW (2005) Effects of diets containing linoleic acid- or oleic acid- rich oils on ruminal fermentation and nutrient digestibility, and performance and fatty acids composition of adipose and muscle tissues of finishing cattle. J Anim Sci 83:1312-1321 
Kenyon CN, Stanier RY (1970) Possible evolutionary significance of polyunsaturated fatty acids in blue-green algae. Nature 227:1164-1166

Kuntz R, Kubalek C, Ruf T, Tataruch F, Arnold W (2006) Seasonal adjustment of energy budget in a large wild mammal the Przelwaski horse (Equus ferus przewalskii). J Exp Biol 209:4557-4565

Leiber F, Meier JS, Burger B, Wettstein HR, Kreuzer M, Hatt JM, Clauss M (2008) Significance of coprophagy for the fatty acid profile in body tissues of rabbits fed different diets. Lipids 43:853-865

Mattos R, Staples CR, Thatcher WW (2000) Effects of dietary fatty acids on reproduction in ruminants. Rev Reprod 5:38-45

McWilliams SR, Guglielmo C, Pierce B, Klaassen M (2004) Flying, fasting and feeding in birds during migration: a nutritional and physiological ecology perspective. J Avian Biol 35:377-393

Meluchova B, Blasko J, Kubinec R, Gorova R, Dubravska J, Margetin M, Sojak L (2008) Seasonal variations in fatty acids composition of pasture forage plants and CLA content in ewe milk fat. Small Rumin Res 78:56-65

Miller GJ, Rice RW (1967) Lipid metabolism in lambs as affected by fattening rations of roughage and concentrate. J Anim Sci 26:1153-1159

Milton K (1979) Factors influencing leaf choice by howler monkeys: a test of some hypotheses of food selection by generalist herbivores. Am Nat 114:362-378

Nickel R, Schumer A, Seiferle G (1984) Lehrbuch der Anatomie der Haustiere. Paul Parey, Berlin

Palmquist DL, Jenkins TC (1980) Fat in lactation rations: review. J Diary Sci 63:1-14

Pinheiro J, Bates D, DebRoy S, Sarkar D, the R Core team (2009) nlme: linear and nonlinear mixed effects models. $\mathrm{R}$ package version 3.1-96

R Development Core Team (2010) R: a language and environment for statistical computing. R Foundation for Statistical Computing, Vienna, Austria, ISBN 3-900051-07-0, http://www.R-project.org
Reichlin T, Klansek E, Hackländer K (2006) Diet selection by hares (Lepus europaeus) in arable land and its implications for habitat management. Eur J Widl Res 52:109-118

Ruf T, Arnold W (2008) Effects of polyunsaturated fatty acids on hibernation and torpor: a review and hypothesis. Am J Physiol Regul Integr Comp Physiol 294:R1044-R1052

Ruf T, Valencak T, Tataruch F, Arnold W (2006) Running speed in mammals increases with muscle $n-6$ polyunsaturated fatty acid content. PLoS One. doi:10.1371/journal.pone.0000065

Suchentrunk F, Willing R, Hartl GB (1991) On eye lens weights and other age criteria of the Brown Hare (Lepus europaeus Pallas, 1778). Mammal Biol 56:365-374

Tufarelli V, Valentini L, Dario M, Laudadio V (2010) Effect of n-3 and $n-6$ polyunsaturated fatty acids on hare reproductive performances. Animal. doi:10.1017/S1751731109991741

Valencak TG, Ruf T (2007) N-3 polyunsaturated fatty acids impair lifespan but have no role for metabolism. Aging Cell 6:15-25

Valencak TG, Ruf T (2009) Energy turnover in European hares is centrally limited during early, but not during peak lactation. J Comp Physiol 179:933-943

Valencak TG, Arnold W, Tataruch F, Ruf T (2003) High content of polyunsaturated fatty acids in muscle phospholipids of a fast runner, the European brown hare (Lepus europaeus). J Comp Physiol B 173(8):695-702

Valencak TG, Tataruch F, Ruf T (2009) Peak energy turnover in lactating European hares: the role of fat reserves. J Exp Biol 212:231-237

Vlaemink B, Fievez V, Cabrita ARJ, Fonseca AJM, Dewhurst RJ (2006) Factors affecting odd- and branched-chain fatty acids in milk: a review. Anim Feed Sci Technol 131:389-417

Wathes DC, Abayasekara DRE, Aitken RJ (2007) Polyunsaturated fatty acids in male and female reproduction. Biol Reprod 77:190-201

Zörner H (1996) Der Feldhase. Spektrum Akademischer, Heidelberg 